\title{
Rolf Werner
}

\section{Oktober 1933 25. Februar 2017}

Rolf Werner, Dipl.-Chemiker, aus Michelbach am Wald (Stadt Öhringen, Hohenlohekreis) war langjähriges Mitglied des Historischen Vereins für Württembergisch Franken und von 2002 bis 2012 Leiter des Arbeitskreises „Archäologische Denkmalpflege“ des Historischen Vereins.

Werner wurde am 17. Oktober 1933 in Koblenz geboren. Im Zweiten Weltkrieg brachten ihn seine Eltern in das von Bombenangriffen weniger gefährdete Hohenloher Land, nach Michelbach am Wald, wo

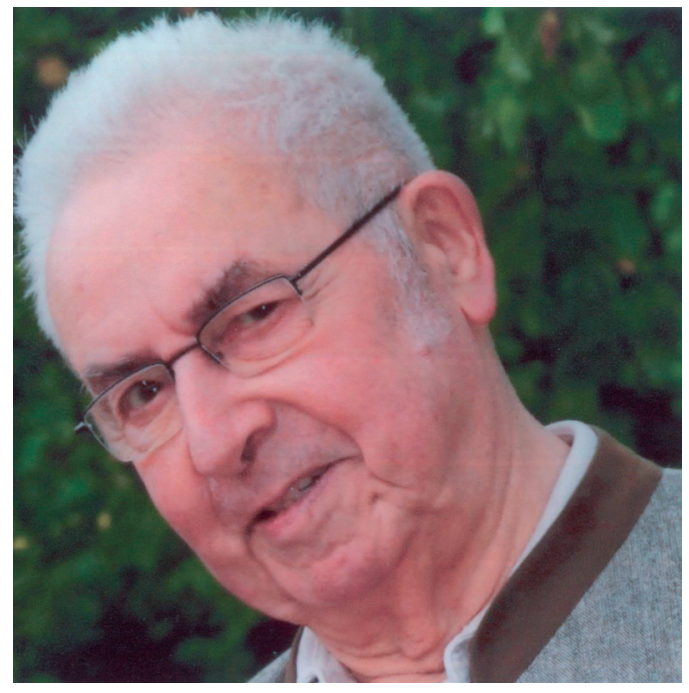
die Großmutter mütterlicherseits wohnte. Michelbach am Wald sollte ihm dann letztendlich auch zum Lebensmittelpunkt werden. Er besuchte das Progymnasium in Öhringen, legte in Heilbronn das Abitur ab, studierte danach an der Technischen Hochschule Stuttgart Chemie und arbeitete anschließend als Chemiker am Max-Planck-Institut in Stuttgart.

1971 heiratete er seine Frau Ruth, die aus Oberschlesien stammt und mit ihrer Familie als Heimatvertriebene nach Michelbach gekommen ist. Ihr Vater, Förster von Beruf, war in Oberschlesien für die Verwaltung des dortigen Hohenlohischen Waldbesitzes zuständig.

Werner interessierte sich schon von klein auf für die Geschichte, für die seines Wohnortes, wo es einst eine Wasserburg gegeben hat, die des Hohenloher Landes, aber auch ganz allgemein für die Zeitgeschichte. So hat er zum Beispiel 1975, als er noch in Stuttgart tätig und durch die Folgen eines Bromgasunfalls im Labor gesundheitlich beeinträchtigt war, regelmäßig als Zuhörer an den Gerichtsverhandlungen der Stammheimprozesse teilgenommen.

Im Ruhestand widmete er sich schließlich eigenen Forschungen. Er recherchierte im evangelischen Pfarrarchiv über die Bevölkerung Michelbachs und transkribierte im Lauf der Zeit alle dort verwahrten Quellen wie zum Beispiel die Kir- 
chenbücher, sodass - wie der frühere Pfarrer der Kirchengemeinde berichtet - er wie auch praktisch jeder andere paläographisch ungeübte Nutzer den Inhalt der Archivalien nachlesen konnte bzw. kann.

Werner war - wenn es seine Gesundheit erlaubte (er litt seit seiner Kindheit an Asthma) - jeden Freitag als Benützer im Hohenlohe-Zentralarchiv in Neuenstein und studierte dort die Quellen. Er engagierte sich auch in verschiedenen geschichtlichen Arbeitskreisen, so zum Beispiel der AG, die für Öhringen ein Häuserbuch herausgegeben hat, und über Michelbach am Wald verfasste er einen Bildband.

Als 2002 der Historische Verein für seinen Arbeitskreis „Archäologische Denkmalpflege" einen neuen Leiter suchte - Horst Clauß musste aus gesundheitlichen Gründen die Leitung abgeben -, stellte sich Werner für dieses Amt zur Verfügung. Seiner Interessenlage und der der meisten Teilnehmerinnen und Teilnehmer des Arbeitskreises entsprechend, fächerte er das Veranstaltungsangebot breiter auf. Der Archäologie blieb der jährlich in Pfedelbach-Untersteinbach stattfindende Vortrag vorbehalten. Fanden in der Gegend archäologische Ausgrabungen statt, wurden diese besichtigt. Darüber hinaus organisierte er für seine Gruppe interessante Führungen in vielen, zum Teil wenig bekannten historischen Baudenkmälern Hohenlohes (Kirchen, Schlösser, Burgen, Mühlen etc.), die in der Regel nicht öffentlich zugänglich sind. Dabei kamen ihm sein umfangreiches historisches Wissen, seine Freundlichkeit und Herzlichkeit, aber auch die Bekanntschaft mit manchem Adligen aus der Schulzeit zugute. Er legte den Schwerpunkt seines Veranstaltungsprogramms auf die Kulturgeschichte und gewann dadurch manch neuen „Hohenlohefan“. Der Arbeitskreis war offen für jederman, und die Veranstaltungen konnten ohne Anmeldung besucht werden. Der „harte Kern" seiner historisch interessierten Freundinnen und Freunde, die auch weite Anfahrtswege zu den Veranstaltungeszielen in Kauf nahmen, traf sich in bestimmten Abständen zu einem „Stammtisch-Essen“ in Mainhardt-Gaisbach, wo dann auch ein reger Gesprächs- und Gedankenaustausch stattfand. Er war seinen Mitmenschen herzlich und vertrauensvoll zugewandt.

Rolf Werner verstarb nach kurzer Krankheit am 25. Februar 2017 im Alter von 83 Jahren.

Der Historische Verein hat in ihm einen hochgeschätzten treuen Freund verloren.

Tobias Bär/Herta Beutter 